\title{
KUAT TEKAN BEBAS TANAH LEMPUNG BUKIT RAWI DISTABILISASI PASIR DAN SEMEN
}

\author{
ANWAR MUDA \\ Balai Besar Pelaksanaan Jalan Nasional VII \\ Kementerian Pekerjaan Umum dan Perumahan Rakyat \\ Email : anwarmuda@gmail.com
}

\begin{abstract}
Bukit Rawi clay soil properties only have a value of UCS at $0: 41 \mathrm{~kg} / \mathrm{cm}^{2}$ so it does not meet the technical requirements Lapis Foundation Under Highway. To that end, will be improved with the addition of sand and cement and is expected to meet the technical requirements highway pavement. The aim of this study was to determine how much the addition of sand and cement on clay soil stabilization Bukit Rawi for pavement highway.

The results showed that after the addition of $12 \%$ sand with cement $2 \%$, the value of UCS rose to $0: 49 \mathrm{~kg} / \mathrm{cm}^{2}$ of initial conditions $0: 41 \mathrm{~kg} / \mathrm{cm}^{2}$. Then, the addition of $4 \%$ cement, UCS value also increased by $4: 44 \mathrm{~kg} / \mathrm{cm}^{2}$. At addition of cement amounted to $6 \%$, the value of UCS has increased to $5: 29 \mathrm{~kg} / \mathrm{cm}^{2}$ and the addition of cement amounted to $8 \%$, the value of UCS rose to $7: 33 \mathrm{~kg} / \mathrm{cm}^{2}$ and the addition of cement $10 \%$, the value of UCS increased to $9: 06 \mathrm{~kg} / \mathrm{cm}^{2}$. So that, with the addition of sand by $12 \%$ and $8 \%$ of cement optimum technically qualified foundation layer under the highway because of the value of UCS result 7:33 $\mathrm{kg} / \mathrm{cm}^{2}>7: 33 \mathrm{~kg} / \mathrm{cm}^{2}$.
\end{abstract}

Keywords: uncofined compreesive strength, clay, stabilization, sand, cement

\section{ABSTRAK}

Sifat tanah lempung Bukit Rawi hanya memiliki nilai UCS sebesar $0.41 \mathrm{~kg} / \mathrm{cm}^{2}$. sehingga tidak memenuhi syarat teknis Lapis Pondasi Bawah Jalan Raya. Untuk itu, akan dilakukan perbaikan dengan penambahan pasir dan semen dan diharapkan mampu memenuhi syarat teknis perkerasan jalan raya. Tujuan dari penelitian ini adalah untuk mengetahui seberapa besar penambahan pasir dan semen pada stabilisasi tanah lempung Bukit Rawi untuk perkerasan jalan raya.

Hasil penelitian menunjukkan, bahwa setelah dilakukan penambahan pasir sebesar $12 \%$ dengan semen $2 \%$, nilai UCS naik menjadi $0.49 \mathrm{~kg} / \mathrm{cm}^{2}$ dari kondisi awal $0.41 \mathrm{~kg} / \mathrm{cm}^{2}$. Kemudian, penambahan semen $4 \%$, nilai UCS juga mengalami kenaikan sebesar $4.44 \mathrm{~kg} / \mathrm{cm}^{2}$. Pada penambahan semen sebesar $6 \%$, nilai UCS mengalami kenaikan hingga $5.29 \mathrm{~kg} / \mathrm{cm}^{2}$ dan penambahan semen sebesar $8 \%$, nilai UCS naik menjadi $7.33 \mathrm{~kg} / \mathrm{cm}^{2}$ serta penambahan semen $10 \%$, nilai UCS mengalami kenaikan menjadi 9.06 $\mathrm{kg} / \mathrm{cm}^{2}$. Sehingga, dengan penambahan pasir sebesar $12 \%$ dan semen optimum $8 \%$ memenuhi syarat teknis lapis pondasi bawah jalan raya karena nilai UCS hasil $7.33 \mathrm{~kg} / \mathrm{cm}^{2}>7.33 \mathrm{~kg} / \mathrm{cm}^{2}$.

Kata kunci : kuat tekan bebas, tanah lempung, stabilisasi, pasir, semen

\section{PENDAHULUAN}

Stabilisasi tanah adalah pencampuran tanah dengan bahan tertentu, guna memperbaiki sifat-sifat teknis tanah atau dapat pula, stabilisasi tanah adalah usaha untuk merubah atau memperbaiki sifat-sifat teknis tanah agar memenuhi syarat teknis tertentu. Sifat-sifat teknis tanah seperti kuat tekan bebas (UCS) tanah lempung umumnya sangat rendah. Seperti tanah lempung Ciawi (UCS) 0,65 kg/ $\mathrm{cm}^{2}$ (Wahjuningsih, 1997), tanah lempung Indramayu (UCS) 0,195 $\mathrm{kg} / \mathrm{cm}^{2}$ (Sudirja, 2008) dan UCS tanah lempung Bukit Rawi 0,43 kg/cm² (Muda, 2011). Namun jika dilihat besaran kuat tekan bebas tanah tersebut 
maka tanah tersebut termasuk lempung sangat lunak sampai sedang dengan nilai UCS $0-1,00$ $\mathrm{kg} / \mathrm{cm}^{2}$ (Hardiyatmo, 2006).

Permasalahan rendahnya kuat tekan bebas (UCS) tanah lempung Bukit Rawi disebabkan tanah ini mempunyai Indeks plastisitas (PI) $16,81 \%$ dengan penilaian umum sebagai tanah dasar sedang sampai buruk

Melihat permasalahan di atas, pada penelitian ini akan dilakukan peningkatan kuat tekannya (ucs) distabilisasi pasir dan semen. Campuran pasir direncanakan $12 \%$ terhadap berat isi kering lempung. Kemudian, pembuatan campuran semen dengan lempung dan pasir yang sudah tercampur pada kondisi optimum. Campuran semen direncanakan 2, 4, 6, 8 dan $10 \%$ terhadap berat isi kering campuran lempung dan pasir. Pada campuran tersebut dilakukan pengujian UCS untuk subgrade jalan raya.

\section{Stabilisasi Pasir}

Stabilisasi menggunakan campuran pasir bertujuan untuk mengukur perubahan indeks plastisitas (PI). Hicks, 2002 (dalam Hardiyatmo, 2010) menyebutkan, tanah berbutir halus seperti lempung jika distabilisasi dengan semen sebaiknya tanah tersebut bila uji saringan No. 200 $\geq 25 \%$ maka indeks plastisitas $(\mathrm{PI}) \leq 10 \%$. Jika tanah tersebut bilia uji saringan No. $200<25 \%$ maka indeks plastisitas $(\mathrm{PI}) \leq 10 \%$ atau $\mathrm{PI} \geq 10 \%$ atau $\mathrm{PI} \leq 6(\mathrm{PI} \times$ persen lolos saringan No. $200 \leq$ 60 seperti pada Tabel 1.
Tabel 1. Petunjuk awal untuk pemilihan metode stabilisasi

\begin{tabular}{|c|c|c|c|c|c|c|}
\hline $\begin{array}{c}\text { Material lolos } \\
\text { saringan } \\
\text { No.200 } \\
\end{array}$ & \multicolumn{3}{|c|}{$\begin{array}{c}>25 \% \text { lolos } \\
\text { saringan No.200 } \\
(0,075 \mathrm{~mm})\end{array}$} & \multicolumn{3}{|c|}{$\begin{array}{c}<25 \% \text { lolos saringan } \\
\text { No.200 (0,075 mm) }\end{array}$} \\
\hline $\begin{array}{c}\text { Indeks } \\
\text { plastisitas } \\
\text { PI (\%) }\end{array}$ & $\leq 10$ & $10-20$ & $\geq 20$ & $\begin{array}{c}\leq 6(\mathrm{Pl}) \mathrm{x} \\
\text { persen } \\
\text { lolos } \\
\text { saringan } \\
\text { No.200 } \\
\leq 60\end{array}$ & $\leq 10$ & $\geq 10$ \\
\hline \multicolumn{7}{|l|}{$\begin{array}{l}\text { Bentuk } \\
\text { Stabilisasi : }\end{array}$} \\
\hline $\begin{array}{l}\text { Semen dan } \\
\text { Campuran } \\
\text { pengikat }\end{array}$ & Cocok & Ragu & $\begin{array}{l}\text { Tidak } \\
\text { Cocok }\end{array}$ & Cocok & Cocok & Cocok \\
\hline Kapur & Ragu & Cocok & $\begin{array}{l}\text { Tidak } \\
\text { Cocok }\end{array}$ & $\begin{array}{l}\text { Tidak } \\
\text { Cocok }\end{array}$ & Ragu & Cocok \\
\hline $\begin{array}{l}\text { Aspal } \\
\text { (bitumen) }\end{array}$ & Ragu & Ragu & $\begin{array}{l}\text { Tidak } \\
\text { Cocok } \\
\end{array}$ & Cocok & Cocok & Ragu \\
\hline $\begin{array}{l}\text { Aspal/semen } \\
\text { dicampur }\end{array}$ & Ragu & Ragu & \begin{tabular}{|l|} 
Tidak \\
Cocok \\
\end{tabular} & Cocok & Cocok & Ragu \\
\hline Granular & Cocok & $\begin{array}{l}\text { Tidak } \\
\text { Cocok } \\
\end{array}$ & \begin{tabular}{|l|} 
Tidak \\
Cocok \\
\end{tabular} & Cocok & Cocok & Ragu \\
\hline $\begin{array}{l}\text { Lain-lain } \\
\text { campuran }\end{array}$ & \begin{tabular}{|c|} 
Tak \\
Cocok \\
\end{tabular} & C & Cocok & Ragu & Ragu & Cocok \\
\hline
\end{tabular}

Sumber : Hicks, 2002 (dalam Hardiyatmo, 2010).

\section{Stabilisasi semen}

Kriteria stabilisasi tanah menggunakan semen menurut maksud dan penggunaannya yang diusulkan oleh Ingels dan Metcalf (1972) dalam Tabel 2. dan kriteria kekuatan stabilisasi tanah semen untuk Lapis Pondasi Bawah (LPB) dan Lapis Pondasi Atas (LPA) oleh Ditjen Bina Marga yang didasarkan pada SNI 03-3438-1994 (dalam Hardiyatmo, 2010) dalam Tabel 3.

Tabel 2. Kriteria stabilisasi tanah menggunakan semen

\begin{tabular}{|c|c|c|c|c|c|c|}
\hline \multirow{2}{*}{\multicolumn{2}{|c|}{ Purpose }} & \multicolumn{2}{|c|}{ U.C.S."I] } & \multirow[t]{2}{*}{ C.B.R. ${ }^{(2)}$} & \multirow{2}{*}{\begin{tabular}{|r|} 
Swell \\
per cent
\end{tabular}} & \multirow{2}{*}{$\begin{array}{c}\begin{array}{c}\text { Loss in } \\
\text { wet/dry test }\end{array} \\
\text { per cent }\end{array}$} \\
\hline & & $\mathrm{kg} / / \mathrm{cm}^{2}$ & $\left(\mathrm{ibt} / \mathrm{in}^{2}\right)$ & & & \\
\hline \multicolumn{2}{|c|}{$\begin{array}{l}\text { Road sub-base, formation } \\
\text { backfill for trenches etc. } \\
\text { Road sub-base, base for } \\
\text { light traftic }{ }^{(4)} \\
\text { Base for heavy traftic }{ }^{[4]} \\
\text { Building blocks } \\
\text { Embankment protection } \\
\text { Floodways (too strong for } \\
\text { general use under thin } \\
\text { surtacings) }\end{array}$} & $\begin{array}{c}3.5-10.5 \\
7-14 \\
14-56\end{array}$ & $\begin{array}{l}(50-150) \\
(100-200) \\
(200-800)\end{array}$ & $\begin{array}{c}20-80 \\
50-150 \\
200-600\end{array}$ & $\begin{array}{l}2 \\
2\end{array}$ & $\begin{array}{l}7 \\
10\end{array}$ \\
\hline \multicolumn{7}{|c|}{$\begin{array}{l}\text { (1) U.C.S. cured seven days at constant moisture content. The loss of strength on } \\
\text { soaking should not be more than } 20 \text { per cent. }\end{array}$} \\
\hline [2] & \multicolumn{6}{|c|}{ C.B.R. - Soaked four days. } \\
\hline โЭ] & \multirow{2}{*}{\multicolumn{6}{|c|}{$\begin{array}{l}\text { Durability test appropriate only where moisture penetration is likely to occur. } \\
\text { Higher cement contents may be required to meet this criterion. } \\
\text { Lower strengths may be adequate for well-drained areas in the tropics. }\end{array}$}} \\
\hline [4] & & & & & & \\
\hline \multicolumn{7}{|c|}{ Sumber : Ingels dan Metcalf (1972) } \\
\hline
\end{tabular}


Tabel 3. Kriteria kekuatan stabilisasi tanah semen

\begin{tabular}{ccc}
\hline Uraian & $\begin{array}{c}\text { Kuat Tekan } \\
\left.\text { Bebas } \mathbf{( k g / \mathbf { c m } ^ { 2 }}\right)\end{array}$ & $\begin{array}{c}\text { CBR } \\
(\%)\end{array}$ \\
\hline $\begin{array}{c}\text { Lapis Pondasi Atas (LPA) } \\
7 \text { hari }\end{array}$ & 22 & 80 \\
$\begin{array}{c}\text { Lapis Pondasi Bawah (LPB) } \\
7 \text { hari }\end{array}$ & 6 & 20 \\
\hline \begin{tabular}{l} 
hari \\
\hline
\end{tabular}
\end{tabular}

Sumber : Hardiyatmo (2010)

Muda (2011), melakukan penelitian tesis dengan judul Stabilisasi Tanah Lempung Bukit Rawi Menggunakan Pasir dan Semen. Penelitian dilatarbelakangi dengan bentuk mengangkat permasalahan rendahnya daya dukung tanah. Dari uji analisa saringan, bahwa tanah ini lolos saringan No. 200 sebesar $71.42 \%>50 \%$, sehingga tanah ini termasuk kelompok tanah berbutir halus. Kemudian dari uji daya dukung tanah, bahwa tanah ini memiliki nilai kuat tekan bebas $0.41 \mathrm{~kg} / \mathrm{cm}^{2}$ sehingga tanah ini memiliki konsistensi lempung lunak dan memiliki daya dukung sangat buruk untuk perkerasan jalan raya.

Arif (2006), melakukan penelitian Stabilisasi Tanah Liat Lunak dengan Garam dan Portland Cement (PC), menyatakan, praktis untuk tanah liat lunak asli tak dapat dilakukan karena benda uji tak bisa dibuat. Namun dengan penambahan garam dan semen kondisi tanah menjadi lebih baik sehingga benda uji bisa dibuat.

Hasil pengujian menunjukkan pengaruh kadar garam terhadap nilai UCS masing-masing untuk curing 7, 14 dan 28 hari untuk kadar semen $16 \%$ pada curing 7 hari, UCS meningkat dengan naiknya kadar garam, tapi untuk curing 14 dan 28 hari justru menurun. Untuk kadar PC 13\% nilai UCS berkurang dengan bertambahnya kadar garam pada curing 7, 14 dan 28 hari, disini jelas kuatnya pengaruh curing terhadap hubungan antara UCS dan kadar garam.

\section{METODOLOGI}

Penelitian dillakukan di laboratorium Mekanika Tanah Universitas Muhammadiyah Palangkaraya JI. RTA Milono Km 1,5 Palangka Raya. Metode penelitian ini mengacu pada diagram alir seperti pada Gambar 1.

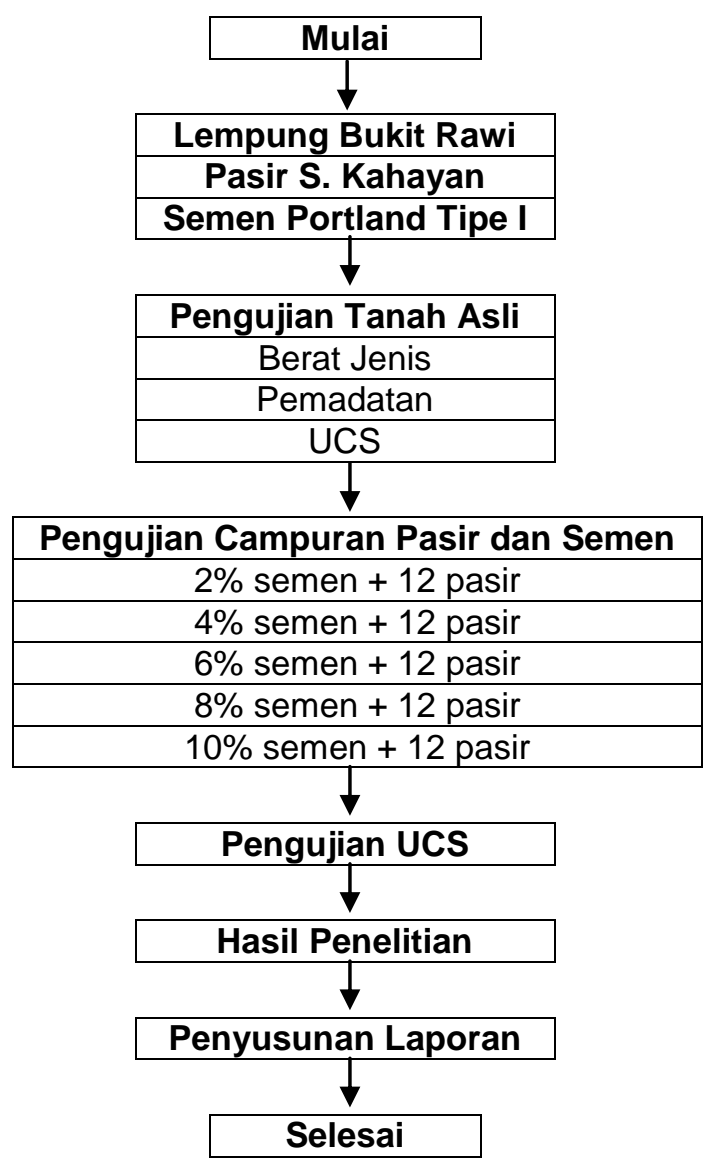

Gambar 1. Diagram Alir Penelitian

\section{HASIL DAN PEMBAHASAN}

\section{Karakteristik Tanah Asli}

Adapun karakteristik tanah asli Bukit Rawi dapat dilihat pada Tabel 4.

Tabel 4. Karakteristik tanah asli Bukit Rawi

\begin{tabular}{ccc}
\hline Tipe Pengujian & Satuan & Hasil \\
\hline Berat jenis & & 2.645 \\
Berat Isi Kering Maks & $\mathrm{gr} / \mathrm{cm}^{3}$ & 1.415 \\
Kadar Air Optimum & $\%$ & 26.60 \\
UCS & $\mathrm{kg} / \mathrm{cm}^{2}$ & 0.41 \\
\hline
\end{tabular}


Berdasarkan Tabel 4. di atas, menurut AASHTO (dalam Hardiyatmo, 2006) bahwa tanah ini termasuk lempung organik karena Gs hasil uji 2,645 berada pada interval 2,58-2,65 (Hardiyatmo, 2006). Sedangkan dari kepadatan tanah diperoleh $1,415 \mathrm{gr} / \mathrm{cm}^{3}$ pada kadar optimum $26,60 \%$. Kemudian pada uji UCS diperoleh 0.41 $\mathrm{kg} / \mathrm{cm}^{2}$. Menurut Bina Marga (dalam Hardiyatmo, 2010), bahwa tanah ini termasuk UCS dengan konsistensi tanah lunak dan memiliki yang untuk subgrade jalan raya.

\section{Karakteristik Tanah Asli} Setelah Distabilisasi Pasir dan Semen

Adapun karakteristik tanah asli Bukit Rawi setelah penambahan pasir dan semen dapat dilihat pada Tabel 5 dan Gambar 2.

Tabel 5. Karakteristik tanah lempung setelah distabilisasi campuran pasir dan semen

\begin{tabular}{ccc}
\hline $\begin{array}{c}\text { Campuran } \\
\text { Pasir (\%) }\end{array}$ & $\begin{array}{c}\text { Campuran } \\
\text { Semen (\%) }\end{array}$ & $\begin{array}{c}\text { UCS } \\
\left(\mathbf{k g} / \mathbf{c m}^{2}\right)\end{array}$ \\
\hline & 2 & 0.49 \\
12 & 4 & 4.44 \\
& 6 & 5.29 \\
& 8 & 7.33 \\
& 10 & 9.06 \\
\hline
\end{tabular}

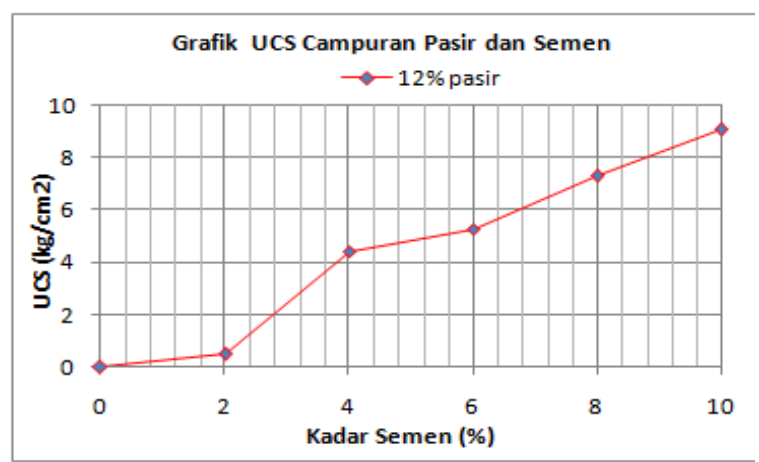

Gambar 2. Grafik UCS Campuran Pasir dan Semen

Pada Tabel 5 dan Gambar 2. terlihat bahwa nilai UCS naik seiring bertambahnya campuran pasir dan semen. Kemudian pada saat stabilisasi tanah lempung dengan campuran $12 \%$ pasir dan $10 \%$ semen nilai diperoleh nilai UCS sebesar 9.06 $\mathrm{kg} / \mathrm{cm}^{2}$. Sehingga, stabilisasi tanah lempung bukit Rawi memenuhi syarat untuk Lapis Pondasi Bawah Jalan Raya karena nilai UCS $9.06 \mathrm{~kg} / \mathrm{cm}^{2}$ $>$ UCS $6 \mathrm{~kg} / \mathrm{cm}^{2}$. Naiknya nilai UCS ini disebabkan penambahan semen menjadi media perekat bila bereaksi dengan air. Media perekat ini kemudian memadat dan membentuk massa yang keras sehingga lebih kuat menahan beban.

\section{KESIMPULAN DAN SARAN}

\section{Kesimpulan}

Hasil penelitian menghasilkan kesimpulan bahwa :

a. Penambahan pasir sebesar $12 \%$ dengan semen $2 \%$, nilai UCS naik menjadi $0.49 \mathrm{~kg} / \mathrm{cm}^{2}$ dari kondisi awal $0.41 \mathrm{~kg} / \mathrm{cm}^{2}$.

b. Penambahan semen $4 \%$, nilai UCS juga mengalami kenaikan sebesar $4.44 \mathrm{~kg} / \mathrm{cm}^{2}$.

c. Penambahan semen sebesar $6 \%$, nilai UCS mengalami kenaikan hingga $5.29 \mathrm{~kg} / \mathrm{cm}^{2}$

d. Penambahan semen sebesar $8 \%$, nilai UCS naik menjadi $7.33 \mathrm{~kg} / \mathrm{cm}^{2}$ serta penambahan semen $10 \%$, nilai UCS mengalami kenaikan menjadi $9.06 \mathrm{~kg} / \mathrm{cm}^{2}$.

\section{Saran}

Penggunaan untuk lapis pondasi bawah jalan raya bisa dilakukan dengan penambahan pasir sebesar $12 \%$ dan semen optimum $8 \%$ karena memenuhi syarat teknis lapis pondasi bawah jalan raya didasarkan karena nilai UCS hasil sebesar $7.33 \mathrm{~kg} / \mathrm{cm}^{2}>7.33 \mathrm{~kg} / \mathrm{cm}^{2}$. 


\section{DAFTAR PUSTAKA}

Hardiyatmo, H.C. 2006. Mekanika Tanah 1, Edisi Keempat, Gajah Mada University Press, Yogyakarta

Ingles, O.G, dan Metcalf, J.B, 1972. Soil stabilization Principle and Practice, Butterworths Pty. Limited, Melbourne.

Moerdika, O.V,. 2002. Stabilisasi Tanah Laterit dari Lampung Untuk Digunakan Sebagai Bahan Lapis Pondasi Perkerasan, Institut Teknologi Bandung.

Punmia, B.C. 1973. Soil Mechanics and Foundation, Laxmi Publication (P), Ltd, New Delhi.

Soedarmo, G.D dan Purnomo, J.D. 1997. Mekanika Tanah 1, Kanisius, Jogjakarta

Sujianto,A.T. 2007. Stabilisasi Tanah Lempung Ekspansif Dengan Garam Dapur ( $\mathrm{NaCl})$ (Jurnal Teknik Sipil Volume 8, No.1, 2007)

Sukirman, S. 1999. Perkerasan Lentur Jalan Raya, Nova, Bandung

Wesley, L.D,. 1977. Mekanika Tanah, Cetakan ke VI, Badan Penerbit Pekerjaan Umum, Jakarta.

Muda, A. 2011. Stabilisasi Tanah Lempung Bukit Rawi Menggunakan Pasir dan Semen, Program Studi Magister Teknik Sipil Universitas Lambung Mangkurat, Banjarmasin. 